\title{
A EVOLUÇÃO DOS INDICADORES DE CUSTO POR ALUNO NA UNIVERSIDADE FEDERAL DE SANTA CATARINA DE 2002 A 2013 CONFORME METODOLOGIA DO TCU
}

\author{
THE EVOLUTION OF THE INDICATORS OF COST PER STUDENT IN THE FEDERAL \\ UNIVERSITY OF SANTA CATARINA FROM 2002 TO 2013 BASED ON THE \\ METHODOLOGY OF TCU
}

\author{
Mariana Campagnoni \\ mari.campa@yahoo.com.br \\ Universidade Federal de Santa Catarina
}

\author{
Orion Augusto Platt Neto \\ orion.platt@ufsc.br \\ Universidade Federal de Santa Catarina
}

\begin{abstract}
RESUMO: As Instituições Federais de Ensino Superior (IFES) brasileiras têm apresentado desde 2002 uma sequência de nove de indicadores de gestão propostos pelo Tribunal de Contas da União (TCU) por meio da Decisão TCU n. ${ }^{\circ}$ 408/2002. O foco desta pesquisa concentra-se no primeiro indicador - custo corrente / aluno equivalente - que a partir de 2006 passou a ser apresentado de duas formas: com e sem custos do Hospital Universitário (HU). Este artigo tem por objetivo apresentar a evolução e considerações sobre os indicadores de custo por aluno da Universidade Federal de Santa Catarina (UFSC) com base na metodologia do TCU entre os anos de 2002 e 2013, considerando os efeitos inflacionários e a influência dos componentes envolvidos. Quanto à abordagem do problema, a pesquisa é qualitativa e quantitativa; em relação aos objetivos, trata-se de uma pesquisa descritiva. Foi procedida a uma pesquisa documental com base em dados reais contidos nos Relatórios de Gestão (RG) da UFSC de 2003 a 2013. No período, observou-se uma elevação nos custos evidenciados pelos indicadores, causada principalmente pelo aumento dos custos correntes totais com e sem HU, considerando que não houve uma variação significativa no número de alunos equivalentes.
\end{abstract}

Palavras-chave: Tribunal de Contas da União. Universidade Federal de Santa Catarina. Indicadores de Desempenho. Custo Corrente por Aluno Equivalente.

ABSTRACT: Since 2002 Federal Institutions of Higher Education (IFES) in Brazil have presented a sequence of nine management indicators proposed by the Federal Court of Audit (TCU) through Decision TCU $n^{\circ}$ 408/ 2002. The focus of this research relies on the first indicator - Current cost / equivalent student - that began to be presented in two ways since 2006, with and without Federal University Hospital (HU) costs. This article aims to present the development and following considerations of the indicators of cost per student of the Federal University of Santa Catarina (UFSC) based on the methodology of TCU from 2002 to 2013, considering the inflationary effects and the influence of the components involved. In terms of the approach to the problem, this is both qualitative and quantitative research. In terms of objectives, this is a descriptive research. This is also a desk research based on actual data contained in UFSC Management Reports (RG) from 2003 to 2013. During this period, there was an increase in costs evidenced by the indicators, mainly caused by the increase of the total current costs with and without HU, whereas there was no significant variation in the number of equivalent students.

Keywords: Federal Court of Audit. Federal University of Santa Catarina. Performance Iindicators. Current Cost per Equivalent Student.

R. Cont. Ufba, Salvador-Ba, v. 9, n. 2, p. 33 - 49, mai-ago 2015 


\section{INTRODUÇÃ̃O}

A partir do ano de 2002 as Instituições Federais de Ensino Superior (IFES) brasileiras passaram a apresentar uma série de indicadores de gestão propostos pelo Tribunal de Contas da União (TCU) por meio da Decisão TCU n. ${ }^{\circ}$ 408/2002. Tal Decisão tem como propósito central a viabilização de avaliações acerca do desempenho das universidades públicas da rede federal.

Determinou-se que, a partir do referido exercício, todas as IFES deveriam apresentar em seu Relatório de Gestão nove indicadores operacionais que, em uma análise simultânea, podem aferir o desempenho das IFES e formar um histórico capaz de se tornar uma ferramenta acessória de controle e autoavaliação (TCU, 2002).

O foco de análise desta pesquisa se concentra no primeiro indicador - custo corrente / aluno equivalente, que a partir da aprovação dos Acórdãos n..$^{\circ}$ 1.043/2006 e n. ${ }^{\circ}$ 2.167/2006, passou a ser apresentado de duas formas: incluindo uma parcela correspondente a $35 \%$ das despesas com manutenção do Hospital Universitário (HU), e excluindo 100\% destas (TCU, 2006).

O uso de indicadores como instrumento de avaliação nas universidades é assunto amplamente debatido. Da mesma forma, há críticas relacionadas à eficácia dos indicadores de gestão pelo TCU (PLATT NETO; VIEIRA, 2006; QUEIROZ et.al., 2013), bem como aos métodos de avaliação do desempenho discente em uso pelo Brasil (DIAS SOBRINHO, 2008; POLIDORI, 2009). No entanto, de acordo com Ferreira, Santos e Passanha (2013), é possível utilizar os indicadores para fins de análise comparativa entre diferentes IFES, não obstante as críticas em relação a sua metodologia.

Com base na perspectiva respaldada pelo TCU de que os indicadores vistos como série histórica podem ser uma poderosa ferramenta de avaliação institucional, obtém-se a questão que conduz a elaboração desta pesquisa: Como os indicadores de custo por aluno da Universidade Federal de Santa Catarina (UFSC), apurados de acordo com a metodologia do TCU, evoluíram entre 2002 e 2013?

Diante do exposto, este artigo tem como objetivo apresentar a evolução e considerações sobre os indicadores de custo por aluno da UFSC com base na metodologia do TCU entre os anos de 2002 e 2013, considerando os efeitos inflacionários e a influência dos componentes envolvidos.

Optou-se por analisar o indicador confome metodologia do TCU por serem eles de publicação obrigatória. A perspectiva advinda da apresentação destes indicadores, de acordo com o próprio órgão, é a de que, futuramente, possa ser traçado um diagnóstico acerca do desempenho do ensino superior, sendo possível verificar a necessidade de aperfeiçoamentos em setores específicos de gestão (TCU, 2002). Nesse sentido, pretende-se analisar as informações que podem ser coletadas por meio destes indicadores, e se elas podem contribuir com a avaliação do desempenho nas IFES, alinhando-se a pesquisas de Freire, Crisóstomo e Castro (2007), Barbosa, Freire e Crisóstomo (2011) e Ferreira, Santos e Pessanha (2013).

$\mathrm{O}$ presente artigo se justifica como contribuição às universidades no que tange à análise evolutiva dos indicadores, a fim de que estes possam ser utlizados como instrumento de acompanhamento de gestão e de controle social. Apesar das críticas apontadas à metodologia do TCU, esta pesquisa pretende contribuir com a literatura ao verificar informações que podem ser coletadas por meio de análise descritiva dos indicadores.

R. Cont. Ufba, Salvador-Ba, v. 9, n. 2, p. 33 - 49, mai-ago 2015 
Os procedimentos metodológicos realizados constam na seção 3, seguidos dos resultados da pesquisa na seção 4 e das conclusões na seção 5. O referencial normativo e teórico e o método de apuração dos indicadores são apresentados a seguir, na fundamentação teórica.

\section{FUNDAMENTAÇÃO TEÓRICA}

\subsection{Indicadores de Desempenho das IFES Estabelecidos pelo TCU}

O uso de indicadores de desempenho como mecanismos de apoio à avaliação de eficiência em universidades não é uma realidade apenas no Brasil, uma vez que diferentes países contemplam este tipo de ferramenta como avaliação da gestão universitária (HEFCE, 1998; BIGGERI, BINI, 2001; YONEZAWA, 2008; YANG; MCCALL, 2014; RYERSON UNIVERSITY, 2014).

No Brasil, com o intuito de criar um histórico que possibilite a análise de desempenho das universidades, foi expedida pelo Tribunal de Contas da União (TCU) a Decisão TCU n. ${ }^{\circ}$ 408/2002 - Plenário, em cuja matéria ficou estabelecida a obrigatoriedade das Instituições Federais de Ensino Superior (IFES) em apresentar, em seus Relatórios de Gestão (RG), uma série de indicadores de desempenho operacional.

A pretensão inicial do trabalho do TCU "abrangia a realização de auditorias operacionais [...] com a finalidade de se obterem dados regionais que pudessem contribuir para a elaboração, no futuro, de diagnóstico na área do ensino superior em nível nacional" (TCU, 2002).

A tarefa de padronizar a aplicação dos indicadores ficou sob responsabilidade do "Grupo de Contato", criado pela própria Decisão e composto por representantes do TCU, da Secretaria da Educação Superior (SESu/MEC) e da Secretaria Federal de Controle Interno (SFC) (GRUPO DE CONTATO, 2007). No relatório de auditoria levantado no período apontado no trabalho, apontou-se algumas observações, uma vez que:

[...] a grande diversidade das Instituições Federais de Ensino Superior do país envolve toda uma gama de peculiaridades que vão das formas de financiamento à oferta de cursos, dedicação à pós-graduação e pesquisa e à prestação de serviços às comunidades em que estão inseridas (TCU, 2002).

À vista disso, a interpretação dos resultados dos indicadores requer cuidado, pois isoladamente eles não fornecem suporte suficiente que permita conclusões acerca do desempenho das IFES. A intenção do trabalho realizado pela auditoria esteve, portanto, direcionada em "prestar auxílio à administração no tocante ao acompanhamento histórico dos seus índices, fornecendo um importante apoio à autoavaliação institucional" (FERREIRA; SANTOS; PESSANHA, 2013, p. 109).

A Decisão n. ${ }^{\circ}$ 408/2002 foi atualizada pelos Acórdãos n. ${ }^{\circ}$ 1.043/2006 e n. ${ }^{\circ}$ 2.167/2006, que determinam os indicadores obrigatórios a serem apresentados pelas instituições públicas. Segundo o Grupo de Contato (2007), são eles:

a) Custo corrente / aluno equivalente: relação entre o custo corrente e o total de alunos. Após os Acórdãos n. ${ }^{\circ}$ 1.043/2006 e n. ${ }^{\circ}$ 2.167/2006, surgiu a obrigatoriedade desse indicador em ser publicado de duas maneiras: a primeira deduz a proporção de $65 \%$ das despesas com Hospital Universitário (HU), e a segunda as deduz em sua totalidade (100\% dos gastos com HU).

R. Cont. Ufba, Salvador-Ba, v. 9, n. 2, p. 33 - 49, mai-ago 2015 
b) Aluno tempo integral / professor equivalente: somatório do número de alunos matriculados nos cursos de graduação, pós-graduação e residência médica em tempo integral dividido pelo número de professores equivalentes.

c) Aluno tempo integral / funcionário equivalente: relaciona o número de alunos em tempo integral, e o número de funcionários equivalentes, com e sem HU.

d) Funcionário equivalente / professor equivalente: divide-se o número de funcionários equivalentes pelo número de professores equivalentes, com e sem HU.

e) Grau de participação estudantil (GPE): indica o número de alunos da graduação em tempo integral (AGTI) em relação ao número de alunos da graduação (AG).

f) Grau de envolvimento discente com pós-graduação (GEPG): representa o quociente entre o número de alunos da pós-graduação e a soma dos alunos da graduação com os da pósgraduação. Verifica, de acordo com Ferreira, Santos e Pessanha (2013), a intensidade com que a universidade está comprometida na manutenção da pós-graduação stricto sensu.

g) Conceito CAPES/MEC para a pós-graduação: demonstra a qualidade dos cursos de pós-graduação stricto sensu conforme avaliação da Coordenação de Aperfeiçoamento de Pessoal de Nível Superior (CAPES).

h) Índice de qualificação do corpo docente (IQCD): Segundo Barbosa, Freire e Crisóstomo (2011), este índice "mensura a qualidade do corpo docente, variando entre 1 e 5". É feita uma ponderação de acordo com o nível de qualificação docente.

i) Taxa de sucesso da graduação (TSG): Relaciona o número de diplomados com o número total de alunos ingressantes.

Este artigo concentra-se na análise do primeiro indicador, o custo corrente / aluno equivalente, cuja apresentação é feita, de maneira aprofundada, na seção a seguir.

\subsection{O Indicador de Custo Corrente por Aluno Equivalente}

A relação dada por este indicador "mede os custos das atividades correntes (manutenção e funcionamento) por aluno equivalente" (FERREIRA; SANTOS; PESSANHA, 2013, p. 109). No entanto, muito se discute acerca da real mensuração do custo de um aluno. A Universidade Federal de Santa Catarina (UFSC, 2012) salienta em seu Relatório de Gestão (RG) que o custo por aluno solicitado pelo TCU inclui custos de alunos da escola de aplicação (ensino fundamental e médio), do núcleo de desenvolvimento infantil e de custos com pesquisa e extensão, excluindo amortização de capital.

Nesse contexto, Platt Neto e Vieira (2006) sugerem que, na falta de indicadores que apontem o custo real médio por aluno, sejam elaborados índices de custos viáveis para uso gerencial ou de avaliação institucional, de modo que sua divulgação ocorra de maneira ampla à sociedade. Magalhães et al. (2010), ao sugerir metodologia para avaliação do custo do aluno, ressaltam a importância de que recursos próprios e/ou obtidos por outras fontes integrem o custo por aluno juntamente com os recursos repassados pelo Tesouro Nacional.

Este artigo não possui a pretensão de levantar questionamentos a respeito da eficácia deste indicador, mas analisar a sua evolução na UFSC considerando a atualização monetária e os componentes envolvidos. Para tanto, apresentam-se no quadro a seguir os componentes que integram o custo corrente total, numerador na relação custo-aluno.

Quadro 1 - Itens componentes do custo corrente total com e sem custos com hospital universitário Custo corrente

Despesas correntes do órgão Universidade, com todas as UGs (unidades gestoras), inclusive hospitais universitários, se houver:

(-) Aposentadorias e reformas do órgão Universidade;

(-) Pensões do órgão Universidade;

(-) Sentenças Judiciais do órgão Universidade;

R. Cont. Ufba, Salvador-Ba, v. 9, n. 2, p. 33 - 49, mai-ago 2015 
(-) Desp. com pessoal cedido - docente do órgão Universidade;

(-) Desp. com pessoal cedido - corpo técnico administrativo (CTA) do órgão Universidade;

(-) Desp. com afastamento país/exterior - docente do órgão Universidade;

(-) Desp. com afastamento país/exterior - corpo técnico administrativo (CTA) do órgão Universidade.

Custo corrente com HU: (-) 65\% das despesas correntes totais do Hospital Universitário (HU) e maternidade, devendo ser consideradas todas as unidades hospitalares cujas despesas estejam incluídas nas despesas correntes da Universidade.

Custo corrente sem HU: (-) 100\% das despesas correntes totais do Hospital Universitário (HU) e maternidade, devendo ser consideradas todas as unidades hospitalares cujas despesas estejam incluídas nas despesas correntes da Universidade.

Fonte: Elaborado pelos autores com base na Portaria TCU n. ${ }^{\circ} 150$ (TCU, 2012).

Observa-se que a diferença entre os dois custos se resume no fato de que o custo corrente com HU considera 35\% das despesas com o Hospital Universitário, visto que uma parcela dos gastos com estas Unidades Gestoras (UGs) é voltada para o ensino. Este percentual é sugerido pelo próprio TCU, o que, no entendimento de Barbosa, Freire e Crisóstomo (2011), envolve certa subjetividade. Considera-se custo corrente com HU o valor do custo corrente, apurado conforme o Quadro 1, incluindo 35\% das despesas referentes ao HU e maternidade. No custo corrente sem HU, são subtraídas todas as despesas relativas ao HU e maternidade.

Nota-se que o custo corrente utilizado na apuração do indicador não corresponde ao valor integral das despesas correntes da Universidade. É feito um ajuste, como pode ser constatado no Quadro 1.

O termo "aluno equivalente" adotado pelo TCU foi baseado, de acordo com a Secretaria de Educação Superior (SESu/MEC, 2005), no modelo inglês elaborado pelo Higher Education Founding Council for England (HEFCE). Tal relatório consiste na separação entre os alunos que se dedicam integralmente à universidade e os que dedicam uma parte de seu tempo em trabalhos ou outras atividades fora deste ambiente. Com isso, cria-se um aluno equivalente que corresponda aos alunos de período integral e aos que estudam meio período (HEFCE, 2010).

Observa-se, portanto, que não se trata de uma divisão simples das despesas pelo número de alunos, pois se considera que um aluno de tempo integral acaba por consumir mais recursos da universidade do que um aluno de meio período. Para Amaral (2004), é importante refletir sobre o modo como o custo de um aluno varia nas universidades, levando em conta as atividades de pesquisa e extensão e quanto isso representa em cada instituição.

O cálculo do aluno equivalente, denominador na fórmula do indicador de custo por aluno, corresponde à soma do número de alunos equivalentes da graduação (AGE) com os alunos da pós-graduação stricto sensu em tempo integral (APGTI) e residentes em tempo integral (ARTI), conforme apresentado no Quadro 2.

Quadro 2 - Equação do total de alunos equivalentes

Total aluno equivalente $=$ AGE + APGTI + ARTI

Onde: $\mathrm{AGE}=$ alunos da graduação equivalentes.

APGTI $=$ alunos da pós-graduação em tempo integral $=2 \times$ APG.

ARTI $=$ alunos da residência médica em tempo integral $=2 \times$ AR.

Fonte: Elaborado pelos autores com base na metodologia apresentada pelo Grupo de Contato (2007).

Os números de APGTI e ARTI equivalem ao dobro do número de alunos da pósgraduação (APG) e de alunos residentes (AR), já que aqueles têm dedicação exclusiva à universidade. O número de AGE deriva da equação do número de alunos da graduação em tempo integral (AGTI) estabelecido pelo Grupo de Contato (2007), coforme Quadro 3, a seguir.

R. Cont. Ufba, Salvador-Ba, v. 9, n. 2, p. 33 - 49, mai-ago 2015 
Quadro 3 - Equação do número de alunos equivalentes da graduação

AGE $=\sum_{\text {todos os cursos }}\left\{\left(\mathrm{N}_{\mathrm{DI}} * \mathrm{D}_{\mathrm{PC}}\right)\left(1+[\right.\right.$ Fator de Retenção] $\left.)+\left(\left(\mathrm{N}_{\mathrm{I}}-\mathrm{N}_{\mathrm{DI}}\right) / 4\right) * \mathrm{D}_{\mathrm{PC}}\right\} *$ [Peso do grupo em que se insere o curso], ou AGE $=$ AGTI $*$ [Peso do grupo em que se insere o curso]

Onde: $A G T I=\Sigma_{\text {todos os cursos }}\left\{\left(\mathrm{N}_{\mathrm{DI}} * \mathrm{D}_{\mathrm{PC}}\right)\left(1+[\right.\right.$ Fator de Retenção] $\left.)+\left(\left(\mathrm{N}_{\mathrm{I}}-\mathrm{N}_{\mathrm{DI}}\right) / 4\right) * \mathrm{D}_{\mathrm{PC}}\right\}$.

$\mathrm{N}_{\mathrm{DI}}=$ número de diplomados, no ano letivo referente ao exercício, em cada curso.

$\mathrm{D}_{\mathrm{PC}}=$ duração padrão do curso de acordo com a tabela da SESu.

$\mathrm{N}_{\mathrm{I}}=$ número de alunos que ingressaram, no ano letivo relativo ao exercício, em cada curso.

Fator de Retenção e Peso do grupo em que se insere o curso: calculados de acordo com metodologia da Secretaria da Educação Superior (SESu).

Fonte: Elaborado pelos autores com base na metodologia apresentada por Grupo de Contato (2007).

O número de AGTI e de AGE se diferem pelo fato de este último considerar o peso do grupo no qual se insere o curso, informação fornecida pela Secretaria da Educação Superior (SESu) (GRUPO DE CONTATO, 2007). Os compontentes apresentados (AR, ARTI, APG, APGTI e AGE) são também denominados pela UFSC (2012) como indicadores primários e seus valores podem ser conferidos na Seção 4.2.

\subsection{Pesquisas Anteriores}

São apresentadas, nesta seção, algumas pesquisas anteriores no que se refere ao estudo do custo do aluno nas universidades públicas, sendo que algumas abordam, outras não, a metodologia do TCU. Ambos os estudos apresentados auxiliaram na construção desta pesquisa e foram utilizados como apoio para a análise dos resultados encontrados.

Amaral (2004) analisou a evolução do custo do aluno nas IFES entre 1995 e 2001, período anterior à implementação da metodologia do TCU. O autor sugeriu uma metodologia própria para o cálculo destes custos, considerando a inflação no período, e observou, como resultado, uma redução no custo do aluno ocasionada pela redução no repasse de recursos às instituições e pelo aumento no número de alunos.

Magalhães et al. (2010) apuraram o custo por aluno no ensino de graduação da Universidade Federal de Viçosa (UFV). Assim como Amaral, os autores propuseram um metodologia própria para o cálculo do custo por aluno, no qual o custo foi apurado por curso, considerando que cursos diferentes possuem custos também diferenciados.

Algumas pesquisas, além de adotarem a metodologia do TCU, utilizaram também amostras para chegar a seus resultados. Freire, Crisóstomo e Castro (2007) e Barbosa, Freire e Crisóstomo (2011) analisaram possíveis relações entre os indicadores do TCU e os de desempenho discente, medido pelo Exame Nacional de Desempenho dos Estudantes (ENADE). A primeira pesquisa não detectou um esperado efeito positivo do custo por aluno no desempenho (FREIRE; CRISÓSTOMO; CASTRO, 2007). A segunda, por sua vez, constatou que o custo por aluno tem, de fato, efeito positivo sobre o desempenho discente (BARBOSA; FREIRE; CRISÓSTOMO, 2011).

Ferreira, Santos e Pessanha (2013) procederam a uma análise comparativa, com base em métodos estatísticos, em 59 IFES, na busca pela identificação de possíveis correlações. Embora o conjunto dos indicadores do TCU não abranja toda a dimensão avaliativa do ensino superior, os autores constataram ser possível a análise comparativa entre universidades, cujos resultados podem contribuir para a literatura nas áreas de controle e gestão dos gastos públicos.

Além disso, é possível verificar estudos que contestem a eficácia dos indicadores do TCU. Platt Neto e Vieira (2006) discutiram acerca de sua metodologia e sugeriram seu aprimoramento. Queiroz et al. (2013), ao analisar o uso dos indicadores, questionaram a

R. Cont. Ufba, Salvador-Ba, v. 9, n. 2, p. 33 - 49, mai-ago 2015 
adequação do custo corrente / aluno equivalente às necessidades das IFES, sugerindo que este seja substituído por um índice mais adequado.

$\mathrm{Na}$ literatura internacional, reconhecendo a necessidade de se construir indicadores apropriados para avaliação da eficiência, efetividade e e qualidade da educação, Biggeri e Bini (2001) propuseram um conjunto de indicadores para uso no sistema universitário Italiano, com base nos quais buscaram uma metodologia apropriada e sem informações redundantes.

Yang e Mccall (2014) examinaram relação entre políticas de financiamento em educação e acesso ao ensino superior, entre 86 países no período de 1998 a 2009, por meio de indicadores internacionais de desempenho. No que se refere ao custo por estudante no ensino superior, os autores constataram que em países desenvolvidos ele costuma ser constante ao longo dos períodos, à medida que em países em desenvolvimento (ou menos desenvolvidos como os próprios autores preferem destacar) este indicador apresenta significativas variações.

O presente estudo dá prosseguimento às pesquisas sobre avaliação de desempenho no ensino superior público por meio de indicadores, neste caso, tratando do indicador de custo por aluno calculado conforme metodologia do TCU. Conforme salientado anteriormente, esta metodologia possui críticas relacionadas à sua construção, mas o referido órgão acredita que os indicadores podem fornecer relevantes informações estratégicas à gestão universitária, especialmente se vistos de forma conjunta e em série histórica. Pretende-se, assim, traçar uma investigação como forma de verificar se estas informações podem, de fato, ser úteis às universidades.

\section{PROCEDIMENTOS METODOLÓGICOS}

\subsection{Enquadramento Metodológico}

Quanto à abordagem do problema, a pesquisa é entendida como qualitativa e quantitativa (mista). Na abordagem qualitativa, buscou-se estudar o comportamento dos indicadores de custo / aluno na série delimitada. É quantitativa por terem sido utilizados mecanismos de cálculos para aferir os resultados.

Em relação aos objetivos, trata-se uma pesquisa descritiva, e como tal concentra seu interesse na "descrição das características de determinada população ou fenômeno ou, então, o estabelecimento de relações entre variáveis" (GIL, 2002, p. 42). Esta pesquisa pretende decrever o comportamento dos indicadores, destacando seus aspectos mais relevantes. Foi procedida a uma pesquisa documental com base em dados reais publicados pela Universidade Federal de Santa Catarina (UFSC) em seus Relatórios de Gestão (RG) referentes aos anos de 2003 a 2012. Classificam-se tais relatórios como fontes de dados secundários, dado que possuem uma análise preliminar por parte da Universidade.

Quanto aos dados coletados, de fontes secundárias, foi feito um ajuste monetário no custo corrente total e no custo corrente por aluno equivalente em todos os anos, a fim de amenizar os efeitos ocasionados pela inflação. Para isso, foi utilizado o Índice Nacional de Preços ao Consumidor Amplo (IPCA), disponível no sítio eletrônico do Instituto Brasileiro de Geografia e Estatística (IBGE).

\subsection{População e Amostra}

Esta pesquisa não apresenta uma amostragem, uma vez que se baseia em apenas uma instituição: UFSC, a qual, isoladamente, não representa todas as Instituições Federais de Ensino Superior (IFES). Conforme relato de auditoria do Tribunal de Contas da União (TCU), 
cada universidade possui características próprias, e a comparação entre seus indicadores pode ocasionar conclusões errôneas (GRUPO DE CONTATO, 2007).

A par disso, busca-se, nesta pesquisa, evidenciar a utilidade do indicador de custo / aluno como ferramenta de controle interno, respeitando as orientações do TCU. Os indicadores são apresentados desde 2002 em relatório, e desde 2006 em série histórica, de forma complementar. A leitura e interpretação de sua variação pode gerar informações de cunho gerencial para as IFES, representando, desta forma, um instrumento de apoio à tomada de decisão na gestão universitária.

\subsection{Instrumentos e Procedimentos de Pesquisa}

Esta pesquisa empregou a documentação para o alcance de seu objetivo. No capítulo 4 são apresentados os resultados obtidos a partir deste instrumento. Os procedimentos para a realização desta pesquisa foram definidos em 6 etapas:

$1^{\text {a }}$ etapa: Revisão de literatura das normas do TCU que regulam os indicadores de desempenho.

$2^{a}$ etapa: Coleta e organização dos itens componentes da custo corrente, numerador na equação custo / aluno, entre 2002 e 2012.

$3^{\text {a }}$ etapa: Coleta e organização do $n .^{\circ}$ de alunos equivalentes, denominador no indicador de custo / aluno no período de 2002 a 2012.

$4^{a}$ etapa: Ajuste nos dados coletados, cujo critério está descrito na seção 4.1 do capítulo de Resultados da Pesquisa.

$5^{\text {a }}$ etapa: Tabulação dos dados em planilha eletrônica e atualização monetária do custo corrente e do indicador custo / aluno com base no IPCA.

$6^{\text {a }}$ etapa: Elaboração de tabelas e gráficos para apresentação e discussão sobre a evolução dos indicadores.

Salienta-se que foi presumida legitimidade nos dados fornecidos pela Universidade nos RG, considerando a impossibilidade dos autores em confirmarem a veracidade dos dados disponibilizados pela Instituição.

\section{RESULTADOS DA PESQUISA}

\subsection{Obtenção e Ajuste dos Dados}

A Universidade Federal de Santa Catarina (atuto) é uma autarquia de regime especial, brasileira, vinculada ao Ministério da Educação, cuja finalidade é promover o conhecimento científico, tecnológico, artístico e filosófico (UFSC, 2011).

A UFSC tem publicado em seus Relatórios de Gestão (RG) todos os indicadores de desempenho solicitados pelo TCU. Contudo, os indicadores referentes ao exercício de 2002 podem ser constatados nos RGs a partir de 2006, ano no qual passaram a ser apresentadas séries históricas dos indicadores (UFSC, 2013).

Além da atualização monetária elucidada na Seção 3, foram feitos alguns ajustes por parte dos autores para que fosse mantida uma maior acurácia na apuração dos dados. O ano de 2002, conforme comentado, teve os custos correntes totais com e sem a parcela do HU e o total de alunos equivalentes apresentados nas séries históricas a partir de 2006. Dessa forma, não se teve acesso aos saldos referentes às despesas correntes e aos componentes que as deduzem.

Nos exercícios de 2003 e 2004 ainda não havia a apresentação do custo por aluno reduzindo $100 \%$ das despesas com $\mathrm{HU}$, logo, tais despesas foram deduzidas. O custo corrente

R. Cont. Ufba, Salvador-Ba, v. 9, n. 2, p. 33 - 49, mai-ago 2015 
total sem HU e o indicador custo corrente / aluno equivalente sem HU de 2003 e 2004, foram, desta forma, coletados nas séries históricas a partir de 2006.

Em 2005 e 2010 constatou-se uma diferença pouco significativa entre os valores apresentados pelos RGs e os saldos calculados, o que não chega a interferir diretamente na análise da evolução dos indicadores. Da mesma forma, alguns indicadores primários (número de alunos residentes e de alunos da pós-graduação) tiveram que ser inferidos nos anos de 2003 e 2004 por não terem sido apresentados, conquanto isso não chegasse a prejudicar a compreensão dos indicadores. Mais detalhes podem ser averiguados na Tabela 1 e no Quadro 4, constantes na próxima seção.

\subsection{Apresentação dos Itens que Compõem o Custo Corrente Total e o Custo Corrente por Aluno Equivalente}

Demonstram-se nesta seção os itens que compõem o custo corrente por aluno equivalente com e sem HU referentes aos exercícios de 2002 a 2013, em valores ajustados pelo IPCA.

Tabela 1 - Composição e evolução do custo corrente total com HU e sem HU de 2002 a 2013 Valores expressos em Milhares de Reais (Reais Mil), atualizados monetariamente pelo IPCA para 31/12/2013.

\begin{tabular}{|c|c|c|c|c|c|c|}
\hline Componentes & $2002(1)$ & $2003(2)$ & $2004(2)$ & $2005(3)$ & 2006 & 2007 \\
\hline Despesas correntes da universidade & ND & 666.554 & 715.613 & 725.545 & 853.749 & 872.833 \\
\hline (-) $65 \%$ das despesas correntes do & ND & 52.930 & 53.154 & 76.149 & 85.436 & 84.988 \\
\hline (-) $100 \%$ das despesas correntes do & ND & 81.431 & 81.775 & 117.152 & 131.440 & 130.751 \\
\hline (-) Aposentadorias e reformas & ND & 119.338 & 119.593 & 126.314 & 144.757 & 140.478 \\
\hline (-) Pensões & ND & 14.595 & 16.458 & 18.974 & 20.855 & 22.069 \\
\hline (-) Sentenças judiciais & ND & 71.966 & 70.679 & 76.959 & 77.609 & 75.643 \\
\hline (-) Desp. com pessoal cedido & ND & 534 & 677 & 740 & 723 & 1.054 \\
\hline (-) Desp. com pessoal cedido (CTA) & ND & 366 & 85 & 87 & - & 300 \\
\hline $\begin{array}{l}\text { (-) Desp. com afastamento } \\
\text { país/exterior (docente) }\end{array}$ & ND & 7.990 & 8.417 & 7.714 & - & \\
\hline $\begin{array}{l}\text { (-) Desp. com afastamento } \\
\text { país/exterior (CTA) }\end{array}$ & ND & 742 & 970 & 909 & - & \\
\hline Custo corrente com $\mathrm{HU}$ & 436.486 & 398.093 & 445.581 & 417.699 & 524.369 & 548.301 \\
\hline Custo corrente sem HU & 410.297 & 369.592 & 416.960 & 376.696 & 478.365 & 502.538 \\
\hline Componentes & 2008 & 2009 & $2010(4)$ & 2011 & 2012 & 2013 \\
\hline Despesas correntes da unive & 932.207 & 1.058 .066 & 1.239 .543 & 1.217 .836 & 1.303 .999 & 1.367 .750 \\
\hline (-) $65 \%$ das despesas correntes do & 73.606 & 92.150 & 119.645 & 138.684 & 134.047 & 136.427 \\
\hline (-) $100 \%$ das despesas correntes do & 113.240 & 141.769 & 184.070 & 213.360 & 206.227 & 209.888 \\
\hline (-) Aposentadorias e reformas & 156.308 & 166.280 & 193.412 & 205.325 & 218.849 & 263.784 \\
\hline (-) Pensões & 25.331 & 29.031 & 31.509 & 33.205 & 34.511 & 37.849 \\
\hline (-) Sentenças judiciais & 45.330 & 40.465 & 37.601 & 34.915 & 33.651 & 6.873 \\
\hline (-) Desp. com pessoal cedido & 1.218 & 1.028 & 2.180 & 1.043 & 851 & 1.025 \\
\hline $\begin{array}{l}\text { (-) Desp. com pessoal cedido (CTA) } \\
\text { (-) Desp. com afastamento } \\
\text { país/exterior (docente) }\end{array}$ & 498 & 1.056 & 1.451 & 915 & 653 & 819 \\
\hline $\begin{array}{l}\text { (-) Desp. com afastamento } \\
\text { país/exterior (CTA) }\end{array}$ & - & & - & - & - & \\
\hline Custo corrente com $\mathrm{HU}$ & 629.916 & 728.055 & 853.745 & 803.750 & 881.437 & 920.973 \\
\hline Custo corrente sem HU & 590.282 & 678.436 & 789.320 & 729.073 & 809.257 & 847.512 \\
\hline
\end{tabular}

Notas

CTA - Corpo técnico-administrativo. HU - Hospital Universitário.

(1) ND - Não Disponível. As variáveis componentes das despesas referentes ao RG de 2002, até o relatório de 2013, não foram divulgadas. 
(2) Os valores referentes aos 100\% das despesas correntes do HU dos exercícios de 2003 e 2004 foram inferidos pelos autores, haja vista que não constavam nos relatórios dos referidos anos.

(3) Constatou-se na verificação do RG de 2005 que havia uma diferença de R\$106,51 mil (em valores originais) entre os custos correntes com HU e sem HU não computada. Tal resultado representa $0,04 \%$ do total dos custos correntes e não pode ser considerado significativo, mas os autores preferiram manter os valores encontrados a fim de se obter uma maior acurácia na análise dos indicadores de custo/aluno.

(4) No ano de 2010 há uma diferença de R\$ 325,79 mil (em valores originais) entre o total os custos correntes (com e sem HU) mostrados no RG do referido ano e os custos correntes apresentados na série histórica mais recente (2013). Optou-se por manter os valores originais constantes no RG, já que a diferença corresponde a $0,05 \%$ dos custos correntes totais (pouco significativa). O saldos de 2010 incluem valores recebidos de destaques e convênios para fins de pesquisa e extensão.

Fonte: Elaborado pelos autores com base nos Relatórios de Gestão da UFSC (2002 a 2013).

Entre 2003 e 2013 houve um aumento de $131 \%$ no custo corrente com HU, e de $129 \%$ no custo corrente sem HU, sendo que as despesas correntes da Universidade computaram uma variação positiva de $105 \%$, passando de $\mathrm{R} \$ 666,55$ milhões para $\mathrm{R} \$ 1,37$ bilhão no período de onze anos.

As despesas referentes ao HU obtiveram um crescimento de $158 \%$ entre 2003 e 2013, com destaque a 2011, ano no qual se constatou a maior parcela de despesa com HU se comparado aos demais anos, $\mathrm{R} \$ 213,36$ milhões (18\% das despesas correntes neste ano).

Nos anos de 2003, 2004 e 2005 houve despesas com afastamento de servidores docentes e técnico-administrativos (CTA), as quais passaram a não se repetir nos anos posteriores, mas que podem ter influenciado a redução do custo corrente (com e sem HU) neste período.

Quanto às despesas com pessoal cedido, apenas em 2006 não houve tais gastos no que se refere ao CTA. No quadro 4 é apresentado o segundo item que integra o indicador, o número total de alunos equivalentes em cada ano, juntamente com os indicadores primários que o compõem.

Quadro 4 - Composição e evolução do número total de alunos equivalentes - 2002 a 2013

\begin{tabular}{|c|c|c|c|c|c|c|}
\hline Indicadores Primários & 2002 & 2003 & 2004 & 2005 & 2006 & 2007 \\
\hline $\mathbf{A R}$ & ND & $50(1)$ & $53(1)$ & 56 & 62 & 68 \\
\hline ARTI $=(2 \times A R)$ & ND & 100 & 106 & 112 & 124 & 136 \\
\hline APG & ND & $7.121(2)$ & $5.269(2)$ & 5.127 & 4.937 & 6.601 \\
\hline APGTI $=(2 \times$ APG $)$ & ND & 14.242 & 10.538 & 10.254 & 9.874 & 13.202 \\
\hline AGE & ND & 26.307 & 25.687 & 25.367 & 25.507 & 26.978 \\
\hline $\begin{array}{c}\text { Total alunos equivalentes }= \\
\text { AGE + APGTI + ARTI }\end{array}$ & 39.890 & 40.649 & 36.331 & 35.733 & 35.505 & 40.316 \\
\hline Indicadores Primários & 2008 & 2009 & 2010 & 2011 & 2012 & 2013 \\
\hline $\mathbf{A R}$ & 74 & 75 & 75 & 90 & 133 & 149 \\
\hline ARTI $=(2 \times A R)$ & 148 & 150 & 150 & 180 & 266 & 298 \\
\hline APG & 5.888 & 6.242 & 6.069 & 6.564 & 6.084 & 6.241 \\
\hline APGTI $=(2 \times$ APG $)$ & 11.776 & 12.484 & 12.138 & 13.128 & 12.168 & 12.842 \\
\hline AGE & 27.383 & 26.859 & 31.019 & 30.813 & 30.031 & 30.607 \\
\hline $\begin{array}{c}\text { Total alunos equivalentes }= \\
\text { AGE + APGTI + ARTI }\end{array}$ & 39.307 & 39.493 & 43.307 & 44.121 & 42.465 & 43.737 \\
\hline
\end{tabular}

Notas

(1) Valores inferidos a partir da fórmula do ARTI e do APGTI, uma vez que não constavam nos RG dos referidos exercícios.

(2) Variação de 2003 a 2013, considerando que os valores referentes a 2002 não estavam disponíveis.

Fonte: Elaborado pelos autores com base nos Relatórios de Gestão da UFSC (2002 a 2013).

R. Cont. Ufba, Salvador-Ba, v. 9, n. 2, p. 33 - 49, mai-ago 2015 
Observa-se que houve uma variação de $198 \%$ no número de alunos residentes (AR), e por conseguinte, de alunos residentes em tempo integral (ARTI) entre 2003 e 2013. Isto permite considerar que talvez tenha ocorrido um incentivo na participação dos alunos nas atividades do HU. Nota-se, contudo, que a variação mais significativa da série se concentra nos três últimos exercícios, sendo que entre 2011 e 2012 a variação foi de 48\%, e nos demais anos ela esteve na média dos $8 \%$.

No número de alunos da pós-graduação (APG), logo, da pós-graduação em tempo integral (APGTI), verificou-se uma queda de 12\% entre 2003 e 2013. O ano de 2003 apontou o maior número de APGTI, 14.242, contra 9.874 em 2006, menor número computado na série.

Quanto ao número de alunos da graduação equivalentes (AGE), é possível averiguar a partir do Quadro 4 o aumento de $16 \%$ entre 2003 e 2013. Ainda assim, este indicador primário apresentou reduções no decorrer dos 11 anos, embora elas não tenham sido maiores que $3 \%$.

No total de alunos equivalentes (AGE + APGTI + ARTI), ocorreu um aumento de $8 \%$ entre 2003 e 2013. Houve um pico de 44.121 no total em 2011, e o menor valor foi de 35.505 referente a 2006, consequência do reduzido número de APGTI. Entre 2002 e 2013, houve um aumento de $10 \%$, tendo em vista que o total de alunos equivalentes registrado em 2002 foi menor que em 2003.

\subsection{Considerações Sobre a Evolução dos Indicadores}

$\mathrm{Na}$ Tabela 2, apresentam-se os saldos referentes ao custo corrente total e ao custo corrente por aluno equivalente, ambos com e sem a parcela do HU, em moeda original e ajustada. Em seguida, tem-se a análise crítica sobre a evolução destes indicadores e como seus componentes a influenciaram.

Tabela 2 - Custo corrente total e custo corrente / aluno equivalente Ajuste feito pelo IPCA até 31/12/2013 nas Colunas de "Ajustada".

\begin{tabular}{|c|c|c|c|c|c|c|c|c|}
\hline \multirow{3}{*}{ Ano } & \multicolumn{4}{|c|}{ Custo Corrente Total (R\$ Mil) } & \multicolumn{4}{|c|}{ Custo Corrente/ Aluno Equivalente $(\mathrm{R} \$ 1,00)$} \\
\hline & \multicolumn{2}{|c|}{ Com HU } & \multicolumn{2}{|c|}{ Sem HU } & \multicolumn{2}{|c|}{ Com HU } & \multicolumn{2}{|c|}{ Sem HU } \\
\hline & Original & Ajustada & Original & Ajustada & Original & Ajustada & Original & Ajustada \\
\hline 2002 & 219.987 & 436.486 & 206.788 & 410.297 & 5.515 & 10.942 & 5.184 & 10.286 \\
\hline 2003 & 222.512 & 398.091 & 206.582 & 369.591 & 5.474 & 9.793 & 5.082 & 9.092 \\
\hline 2004 & 270.094 & 445.582 & 252.745 & 416.961 & 7.434 & 12.264 & 6.957 & 11.477 \\
\hline 2005 & 270.007 & 417.700 & 243.502 & 376.697 & 7.556 & 11.689 & 6.814 & 10.542 \\
\hline 2006 & 353.898 & 524.369 & 322.850 & 478.365 & 9.968 & 14.769 & 9.093 & 13.473 \\
\hline 2007 & 384.104 & 548.301 & 352.045 & 502.537 & 9.527 & 13.600 & 8.732 & 12.465 \\
\hline 2008 & 464.126 & 629.917 & 434.923 & 590.282 & 11.808 & 16.026 & 11.065 & 15.017 \\
\hline 2009 & 563.803 & 728.054 & 525.378 & 678.435 & 14.276 & 18.435 & 13.303 & 17.179 \\
\hline 2010 & 694.901 & 853.744 & 642.463 & 789.320 & 16.046 & 19.714 & 14.835 & 18.226 \\
\hline 2011 & 694.799 & 803.750 & 630.145 & 728.957 & 15.748 & 18.217 & 14.284 & 16.524 \\
\hline 2012 & 808.964 & 881.437 & 742.719 & 809.257 & 19.050 & 20.757 & 17.490 & 19.057 \\
\hline 2013 & 894.908 & 920.973 & 823.526 & 847.512 & 20.456 & 21.052 & 18.825 & 19.373 \\
\hline Variação & $307 \%$ & $111 \%$ & $298 \%$ & $107 \%$ & $271 \%$ & $92 \%$ & $263 \%$ & $88 \%$ \\
\hline
\end{tabular}

Notas:

(1) Variação de 2002 a 2013.

Fonte: Elaborado pelos autores com base nos Relatórios de Gestão da UFSC (2002 a 2013).

R. Cont. Ufba, Salvador-Ba, v. 9, n. 2, p. 33 - 49, mai-ago 2015 
Nota-se que os valores originais apontam uma variação mais significativa em relação aos ajustados, razão pela qual se aconselha a atualização monetária. Nesse caso, atualizaramse os valores de todos os anos para a moeda de 31 de dezembro de 2013.

Um reflexo do ajuste monetário pode ser verificado entre 2002 e 2003, em que os custos correntes com HU em moeda original apresentaram aumento de $1 \%$, mas em moeda ajustada, a redução foi de de $9 \%$. Isto ocorreu porque o ajuste foi feito com base na inflação acumulada de $98,41 \%$ em 2002 , e de $78,91 \%$ em 2003, o que influenciou na redução no indicador de custo corrente / aluno equivalente neste intervalo.

Com base nos dados ajustados, verifica-se que em 2013 os custos correntes totais com e sem HU tiveram um aumento de $111 \%$ e $107 \%$ respectivamente, ou seja, praticamente dobraram o seu valor em relação a 2002.

Os indicadores de custo corrente / aluno equivalente com e sem HU apresentaram um crescimento de $92 \%$ e $88 \%$, respectivamente. Em geral, a tendência foi de crescimento em todos os anos, fato que pode ser visualizado nos Gráficos 1 e 2, mostrados a seguir.

Gráfico 1 - Evolução do custo corrente com e sem HU - 2002 a 2013

Valores em R\$ Milhões originais e atualizados monetariamente pelo IPCA até 31/12/2013.

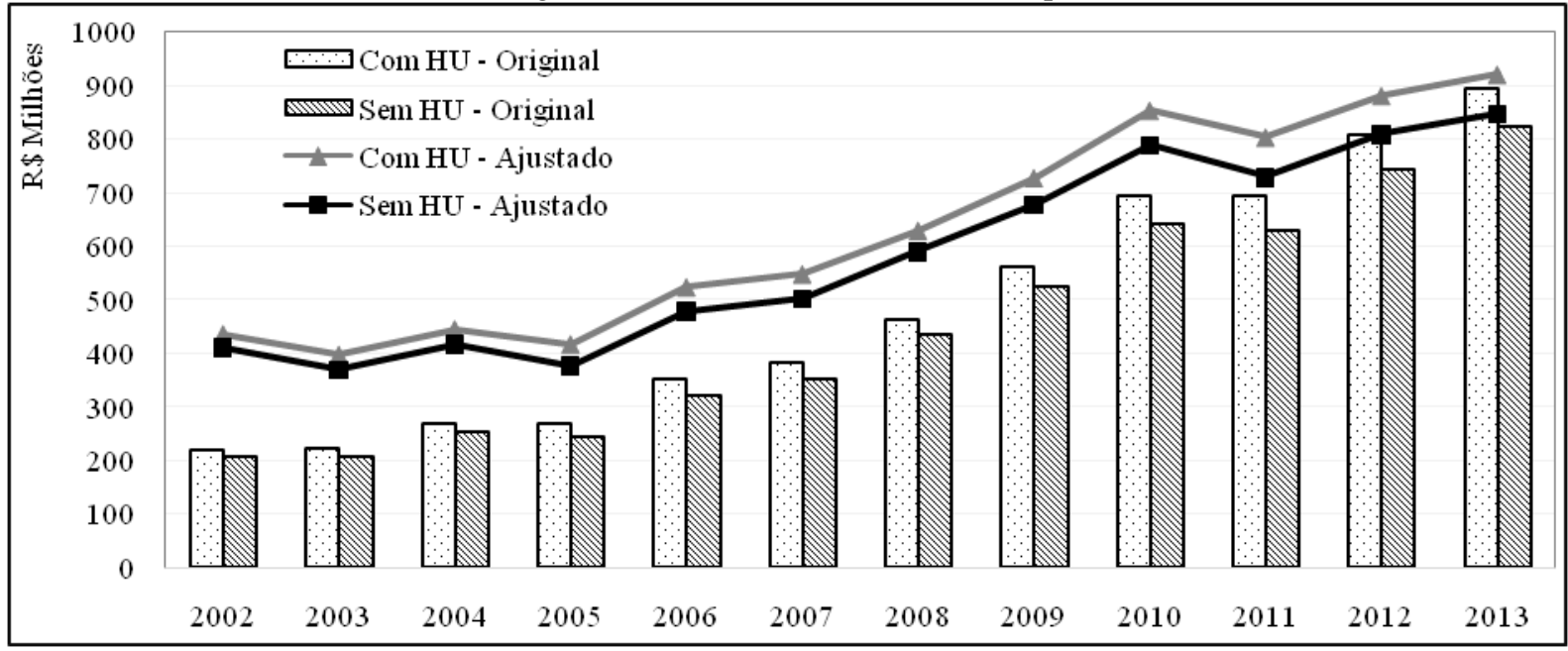

Fonte: Elaborado pelos autores com base nos Relatórios de Gestão da UFSC (2002 a 2013). Tabela 2.

De acordo com o Gráfico 1, observa-se que houve redução, entre 2004 e 2005, de 6\% no custo corrente com HU e de $10 \%$ no custo corrente sem HU, e entre 2010 e 2011 , de $6 \%$ e $8 \%$, respectivamente. Embora o custo corrente com e sem HU, em geral, tenha aumentado, e estas diminuições tenham sido pouco significativas em relação ao custo como um todo, elas acabaram por influenciar as variações do indicador de custo corrrente / aluno equivalente, como pode ser constatado no Gráfico 2.

Gráfico 2 - Evolução dos indicadores de custo corrente / aluno equivalente com e sem HU - 2002 a 2013 Valores em R\$1,00 originais e atualizados monetariamente pelo IPCA até 31/12/2013. 


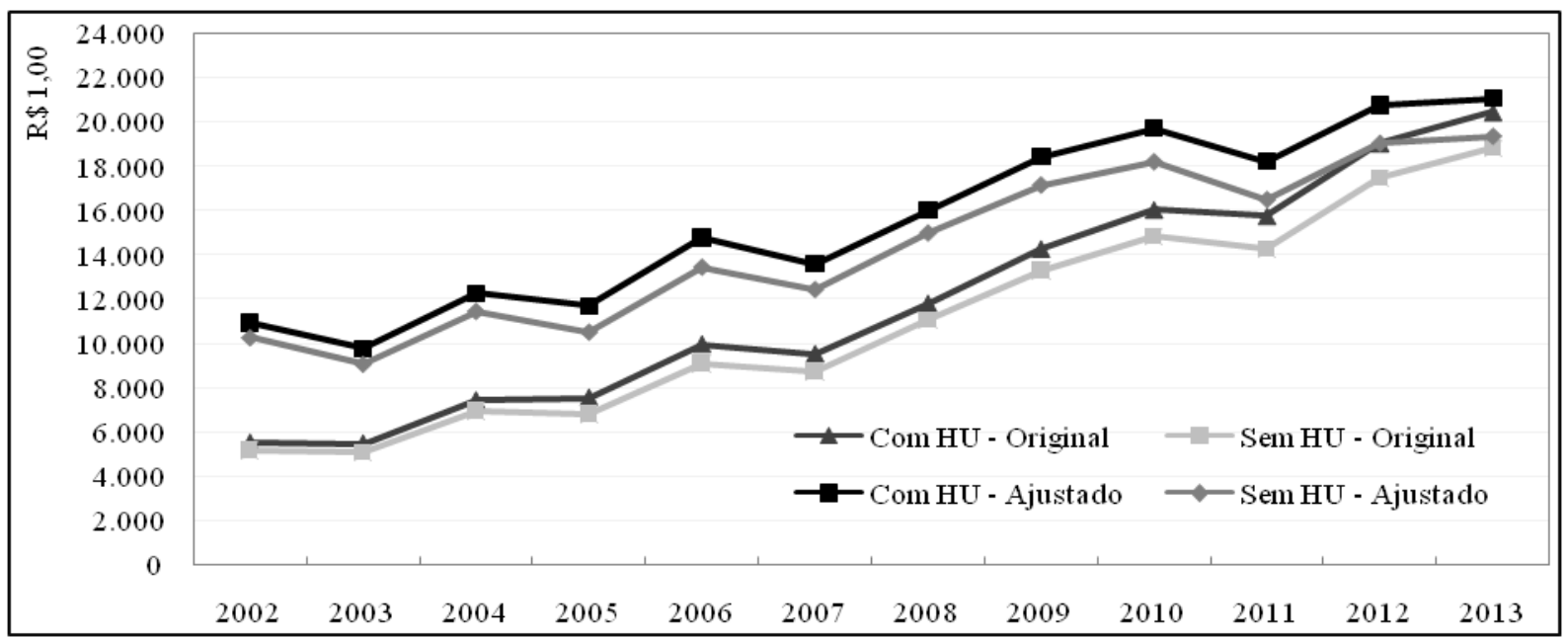

Fonte: Elaborado pelos autores com base nos Relatórios de Gestão da UFSC (2002 a 2013). Tabela 2.

A análise do Gráfico 2, juntamente com os dados contidos nas Tabelas 1 e 2 e no Quadro 4, permite inferir que houve uma variação de $\mathrm{R} \$ 14.941$ ou $271 \%$ no custo corrente / aluno equivalente com HU, e de R $\$ 13.641$ ou $263 \%$ no custo corrente / aluno equivalente sem HU, quando se verificam os valores originais apresentados pelos RG. Entretanto, observa-se nos saldos ajustados que essa variação representa $\mathrm{R} \$ 10.110$ e $\mathrm{R} \$ 9.087$ respectivamente, ou $92 \%$ e $88 \%$, conforme comentado anteriormente.

Entre 2002 e 2003 houve pequena diminuição nos indicadores, consequência da redução de $9 \%$ no custo corrente com HU e de $10 \%$ no custo corrente, sem HU influenciada pelo ajuste monetário. A variação entre os indicadores de 2004 e 2005 se deu por uma redução ocorrida tanto nos custos correntes quanto no número de alunos equivalentes.

O exercício de 2006 aponta um aumento de $26 \%$ nos custos correntes com HU e de $27 \%$ nos custos sem HU contra uma diminuição de $1 \%$ no número de alunos equivalentes em relação ao ano anterior. Este fato ocasionou um crescimento nos indicadores de $26 \%$ e $28 \%$ respectivamente, e não se repetiu em 2007, ano no qual a variação nos custos correntes esteve na média dos 5\% em relação a 2006. Quanto ao número de alunos equivalentes, 2007 apresentou um aumento de 14\%, o maior do período. Tais variações acarretaram uma redução nos indicadores entre 2006 e 2007.

O exercício de 2010 apresentou a peculiaridade de ser o único no qual o custo corrente por aluno equivalente com e sem HU foi publicado de duas formas: com e sem despesas relativas a destaques e convênios.

A UFSC (2010) explica em seu RG que esses custos representam a quantia de R\$ 164,45 milhões recebidos de Ministérios (não especificados) para projetos de pesquisa e extensão. Desconsiderando tal valor, as despesas correntes seriam de R \$ 844,47 milhões. Foram considerados, neste artigo, os custos com destaques e convênios, o que pode ser a razão de os custos correntes totais em 2010 terem sido maiores do que em 2011, o que também refletiu na redução do indicador entre esses dois anos.

Salvos estes casos, a Universidade apresentou, em geral, crescimento nos custos correntes com e sem HU no período analisado, à medida que o número de alunos equivalentes praticamente se manteve estável, dada a baixa variação ocorrida ao longo dos doze anos.

Dessa forma, houve uma tendência de crescimento nos indicadores de custo corrente / aluno equivalente, a qual pode significar que a Universidade tem usado seus recursos para fins de manutenção e funcionamento, o que pode gerar maior qualidade de ensino aos acadêmicos. Visto dessa forma, o crescimento seria um bom indicativo para a UFSC.

Contudo, somente uma pesquisa exploratória na área poderia confirmar se os custos estão sendo utilizados com eficiência. De acordo com Freire, Crisóstomo e Castro (2007), um

R. Cont. Ufba, Salvador-Ba, v. 9, n. 2, p. 33 - 49, mai-ago 2015 
maior custo por aluno deve representar melhorias nas instalações e serviços da instituição de ensino, o que promove um incremento na qualidade na formação acadêmica. Porém, os mesmos autores concluíram em sua pesquisa que o custo do aluno não produz efeito sobre o desempenho discente (FREIRE; CRISÓSTOMO; CASTRO, 2007).

Da mesma forma, discussões acerca da eficácia da metodologia adotada pelo TCU ocorrem desde a aprovação dos indicadores, uma vez que eles podem não representar o real custo do aluno na universidade (PLATT NETO; VIEIRA, 2006). Amaral (2004), ao estudar a evolução do custo do aluno nas IFES no período 1995-2001, observou que ele reduziu entre estes anos. Porém, a metodologia sugerida pelo autor não é a mesma adotada pelo TCU, mesmo havendo algumas semelhanças. Além dos aspectos metodológicos, a série história também é diferente, o que impossibilita uma comparação.

Assim, conquanto a metodologia deste indicador esteja em construção, merecendo ajustes futuros, é possível constatar que a leitura histórica dos indicadores pode fornecer informações estratégicas à avaliação de desempenho da universidade, tais como variações no custo corrente, no número de alunos, e se houve discrepâncias no período (e quais seriam as causas).

É evidente, assim, a possibilidade de a leitura histórica dos indicadores do TCU fornecerem informações complementares, as quais podem ser úteis estrategicamente à universidade. A metodologia adotada pelo órgão, por sua vez, tem sua construção criticada, conforme ressaltado nos capítulos anteriores.

Queiroz et al. (2013) sugerem a substituição deste indicador por outro mais adequado. De fato, suas bases de rateio carecem de comprovações acerca de sua eficácia. $\mathrm{O}$ indicador procura informar o custo por aluno por meio de uma divisão que, embora considere o termo "equivalente" para diferenciar alunos de tempo integral e de meio período, merece, de fato, questionamentos advindos da literatura especializada.

Ademais, não há indícios de rateio por tipo de curso, o que pode levar a uma pressuposição de que todos os cursos possuem o mesmo custo para a universidade. Tal situação foi contraposta por Magalhães et al. (2010), os quais verificaram significativa variação de custos entre os diferentes cursos da Universidade Federal de Viçosa (UFV).

Da mesma forma, considerar que os cursos de graduação possuem os mesmos custos que programas de pós-graduação também é um tópico que merece atenção, pois ambos e diferenciam desde tempo de curso a número de alunos. Por fim, os gastos com HU devem integrar um adequado indicador de custo / aluno se eles representarem, de fato, o gasto com o aprendizado do aluno no hospital. No entanto, é necessária comprovação científica de que esses gastos realmente implicam em 35\% das despesas com HU em todas as IFES. Nesse sentido, embora não seja escopo desta pesquisa a crítica a respeito da eficácia deste indicador, acredita-se que a revisão em sua metodologia pode contribuirá significativamente a sua eficácia.

A evolução deste indicador em conjunto com os demais instituídos pelo TCU pode fornecer uma visão conjunta entre o custo por aluno e o desempenho discente, docente e administrativo universitário. Acredita-se, portanto, que eles podem ser uma ferramenta útil aos usuários, no acompanhamento da gestão universitária, e à sociedade, no acompanhamento do uso dos recursos públicos das IFES.

\section{CONCLUSÕES}

A partir da análise demonstrada, considera-se atingido o objetivo deste artigo, uma vez que se apresentou a evolução dos indicadores de custo por aluno da Universidade Federal de Santa Catarina (UFSC) entre os períodos de 2002 a 2013, calculados conforme a decisão do 
Tribunal de Contas da União (TCU), destacando os aspectos mais relevantes acerca da influência de seus itens componentes.

Observou-se que o indicador de custo corrente por aluno equivalente excluindo $65 \%$ das despesas com Hospital Universitário (HU) obteve um crescimento de 92\% entre 2002 e 2013, enquanto este mesmo indicador desconsiderando 100\% das despesas do HU apresentou um aumento de $88 \%$ no período. Esta variação foi constatada a partir do ajuste monetário dos indicadores, já que os efeitos da inflação fizeram com que tais variações fossem de $271 \%$ e $263 \%$, respectivamente, se considerados os valores originais. O ajuste monetário foi feito com base no Índice Nacional de Preços ao Consumidor Amplo (IPCA). De 2002 a 2013, a inflação acumulada segundo este índice foi de $98,41 \%$.

Verificou-se uma tendência de crescimento nos indicadores ao longo dos doze anos analisados. Considerando que o número de alunos equivalentes não apresentou uma variação significativa no período, pode-se inferir que este crescimento foi ocasionado pelo aumento dos custos correntes totais com e sem HU. Contudo, os indicadores também apresentaram redução em alguns períodos, ora ocasionada pela diminuição nos custos correntes, ora pelo aumento do número de alunos equivalentes.

Desta forma, acredita-se que, apesar das críticas acerca da metodologia adotada pelo TCU, os indicadores podem ser uma ferramenta útil tanto para os usuários, no acompanhamento da gestão universitária, como pela sociedade, no acompanhamento do uso dos recursos públicos das Instituições Federais de Ensino Superior (IFES).

Espera-se que os resultados apresentados sejam úteis em pesquisas futuras cujo escopo seja os custos dos acadêmicos brasileiros e a gestão universitária. Para trabalhos futuros, sugere-se a análise metodológica dos indicadores de custo / aluno e dos fatores que podem ocasionar o aumento nos custos correntes das IFES, tais como os salários dos docentes e servidores técnico-administrativos. Adicionalmente, recomenda-se que esta pesquisa seja expandida às IFES das Regiões Sul e Nordeste do país, com vistas a avaliar a evolução de seus indicadores, e se eles apresentam o mesmo comportamento.

\section{REFERÊNCIAS}

AMARAL, N. C. Evolução do Custo do Aluno das IFES: eficiência? Avaliação, Sorocaba, v. 9, n. 1, p. 115-125, maio 2004. Disponível em: <http://periodicos.uniso.br/ojs/index.php? journal $=$ avaliacao \&page $=$ article $\& o p=$ view $\&$ path $\% 5 \mathrm{~B} \% 5 \mathrm{D}=1272 \&$ path $\% 5 \mathrm{~B} \% 5 \mathrm{D}=1262>$.

Acesso em: 14 jul. 2013.

BARBOSA, G. C.; FREIRE, F. S.; CRISÓSTOMO, V. L. Análise dos indicadores de gestão das IFES e o desempenho discente no ENADE. Avaliação, Sorocaba, v. 16, n. 2, p. 317-343, jul. 2011. Disponível em: <http://www.scielo.br/scielo.php?script=sci_arttext\&pid=S1414$40772011000200005 \& l n g=e n \& n r m=i s o>$. Acesso em: 9 jul. 2013.

BIGGERI, L.; BINI , M. University performance indicators in Italy: the efficiency evaluation using DEA approach. In: Proceedings of the Annual Meeting of the American Statistical Association, 5-9, 2001. Anais... Alexandria: American Statistical Association, 2001.

DIAS SOBRINHO, José. Qualidade, avaliação: do SINAES a índices. Avaliação, Campinas; Sorocaba, SP. v. 13, n. 3, p. 817-825, nov. 2008. Disponível em: <http://www.scielo.br/scielo.php?pid=S1414-40772008000300011\&script=sci_arttext $>$. Acesso em: 03 fev. 2015.

FERREIRA, M. C.; SANTOS, W. J. L.; PESSANHA, J. F. M. Avaliação do ensino superior: análise dos indicadores instituídos pelo TCU para as IFES. Revista de Contabilidade do

R. Cont. Ufba, Salvador-Ba, v. 9, n. 2, p. 33 - 49, mai-ago 2015 
Mestrado em Ciências Contábeis da UERJ, v. 18, n. 1, p. 104-124, abr. 2013. Disponível em: <http://www.spell.org.br/documentos/ver/9940/avaliacao-do-ensino-superior--analisedos-indicadores-instituidos-pelo-tcu-para-as-ifes/i/pt-br>. Acesso em: 9 jul. 2013.

FREIRE, F. S.; CRISÓSTOMO, V. L.; CASTRO; J. E. G. Análise do desempenho acadêmico e indicadores de gestão das IFES. Produção On line, Florianópolis, edição especial, dez. 2007. Disponível em: <http://producaoonline.org.br/rpo/article/view/57/57>. Acesso em: 21 jul. 2013.

GIL, A. C. Como Elaborar Projetos de Pesquisa. 4. ed. São Paulo: Atlas, 2002.

GRUPO DE CONTATO - Tribunal de Contas da União (TCU); Secretaria da Educação Superior (SESu/ MEC); e Secretaria Federal de Controle Interno (SFC). Orientações para o cálculo dos indicadores de gestão: Decisão TCU n. ${ }^{\circ}$ 408/2002 - Plenário e Acórdãos n. ${ }^{\circ}$ 1.043/2006 e n. ${ }^{\circ}$ 2.167/2006 - Plenário. Versão revisada em janeiro/2007. Disponível em: $<$ http://pingifes.mec.gov.br/pingifes/index.php?option=com_docman\&task=searchresult\&ord er=dmdate_published\&ascdesc=DESC\&Itemid=35>. Acesso em: 11 jul. 2013.

HEFCE - Higher Education Funding Council for England. Funding higher education in England: How the HEFCE allocates its funds. September 2010. Disponível em: <http://www.hefce.ac.uk/pubs/year/2008/200833/name,63774,en.html>. Acesso em: 13 jan. 2015.

IBGE - Instituto Brasileiro de Geografia e Estatística. Índice Nacional de Preços ao Consumidor Amplo - IPCA e Índice Nacional de Preços ao Consumidor - INPC. Disponível em: <http://www.ibge.gov.br/home/estatistica/indicadores/precos/inpc_ipca/ipcainpc_201306_1.shtm>. Acesso em: 13 jul. 2013.

MAGALHÃES, E. A. et al . Custo do ensino de graduação em instituições federais de ensino superior: o caso da Universidade Federal de Viçosa. Revista de Administração Pública, Rio de Janeiro, v. 44, n. 3, p. 637-666, jun. 2010. Disponível em: $<$ http://www.scielo.br/scielo.php?script=sci_arttext\&pid=S003476122010000300005\&lng $=$ en\&nrm=iso $>$. Acesso em: 02 jun. 2014.

PLATT NETO, O. A.; VIEIRA, A. L. Análise Metodológica do Indicador de Custo por Aluno Definido pelo Tribunal de Contas da União para as Universidades Federais. In: COLÓQUIO INTERNACIONAL SOBRE GESTÃO UNIVERSITÁRIA NA AMÉRICA DO SUL, 6., 2006, Blumenau. Anais... Blumenau: UFSC, 2006. p.1-13.

POLIDORI, M. M. Políticas de avaliação da educação superior brasileira: Provão, SINAES, IDD, CPC, IGC e... outros índices. Avaliação, Campinas; Sorocaba, SP. v. 14, n. 2, p. 267290, jul. 2009. Disponível em: 〈http://www.scielo.br/pdf/aval/v14n2/a09v14n2.pdf>. Acesso em 05 fev. 2015.

QUEIROZ, I. A. S. et al. Adequação dos indicadores de desempenho adotados pelo Tribunal de Contas da União para avaliação da gestão das Instituições Federais de Ensino Superior da Região Sudeste do Brasil. In: COLÓQUIO INTERNACIONAL SOBRE GESTÃO UNIVERSITÁRIA NA AMÉRICA DO SUL, 13., 2013, Buenos Aires. Anais... Buenos Aires: UFSC, 2013.

RYERSON UNIVERSITY. Ryerson Performance Indicators. March 2014. Disponível em: $<$ http://www.ryerson.ca/content/dam/upo/performance/indicators/PerfIndCURRENT.pdf>. Acesso em: 04 fev. 2015.

SESu/MEC - Secretaria da Educação Superior, do Ministério da Educação. Cálculo do aluno equivalente para fins de custos na manutenção das IFES. Departamento de

R. Cont. Ufba, Salvador-Ba, v. 9, n. 2, p. 33 - 49, mai-ago 2015 
Desenvolvimento da Educação Superior/Tecnologia da Informação, fev. 2005. Disponível em:

http://pingifes.mec.gov.br/pingifes/index.php?option=com_docman\&task=searchresult\&order $=$ dmdate_published\&ascdesc=DESC\&Itemid=35>. Acesso em 12 jul. 2013.

TCU - Tribunal De Contas da União. Decisão TCU n. ${ }^{\circ}$ 408, de 24 de abril de 2002 Plenário. Relator: Iram Saraiva. Disponível em: <https://contas.tcu.gov.br/juris/

Web/Juris/ConsultarTextual2/Processos.faces?>. Acesso em: 9 jul. 2013.

Acórdão TCU n. ${ }^{\circ}$ 1.043, de 28 de junho de 2006 - Plenário. Relator: Guilherme Palmeira. Disponível em: <https://contas.tcu.gov.br/juris/Web/Juris/ConsultarTextual2/ Processos.faces?>. Acesso em: 09 jul. 2013.

Acórdão TCU n. ${ }^{\circ}$ 2.167, de 27 de novembro de 2006 - Plenário. Relator: Ministro Ubir. Disponível em:< https://contas.tcu.gov.br/juris/Web/Juris/ConsultarTextual2/

Processos.faces?>. Acesso em: 09 jul. 2013.

Portaria - TCU n. ${ }^{\mathbf{1}}$ 150, de 3 de julho de 2012. Dispõe sobre orientações às unidades jurisdicionadas ao Tribunal quanto à elaboração dos conteúdos dos relatórios de gestão referentes ao exercício de 2012. Disponível em: <http://portal2.tcu.gov.br/portal/page/portal/ TCU/comunidades/contas/contas_ordinarias_extraordinarias/2012>. Acesso em : 11 jul. 2013. UFSC - Universidade Federal de Santa Catarina. Estatuto 2011. Disponível em: <http:// estrutura.ufsc.br/legislacao/>. Acesso em: 13 jul. 2013.

Estrutura UFSC. 2013. Disponível em: <http://estrutura.ufsc.br/campi/campusflorianopolis/>. Acesso em: 21 jul. 2013.

DPGI - Departamento de Planejamento e Gestão da Informação. 2013. PróReitoria de Planejamento e Orçamento (PROPLAN). Disponível em: <http://dpgi.proplan. ufsc.br/>. Acesso em: 2 maio 2013.

Relatórios de Gestão: referentes aos exercícios de 2002 a 2012. Jun. 2013. Disponível em: <http://dpgi.proplan.ufsc.br/relatorio-de-gestao/>. Acesso em: 2 maio 2013.

Plano de Desenvolvimento Institucional. Breve histórico da UFSC. Publicado em out. 2009. Disponível em: <http://pdi.paginas.ufsc.br/2009/10/28/breve-historico-da-ufsc/>. Acesso em: 21 jul. 2013.

YANG, L.; MCCALL, B. World education finance policies and higher education access: A statistical analysis of World Development Indicators for 86 countries. International Journal of Educational Development, v. 35, p. 25-36, March 2014. Disponível em: <http://www. sciencedirect.com/science/article/pii/S0738059312001459>. Acesso em 02 fev. 2015.

YONEZAWA, A. Quality assessment and assurance in japanese universities: the plight of the social sciences. Social Science Japan Journal, v. 11, n. 1, p. 69-82, 2008. Disponível em: <http://ssjj.oxfordjournals.org/content/11/1/69.short>. Acesso em 28 jan. 2015. 